\title{
Malaria elimination in Haiti: Challenges, progress and solutions
}

Paul Adrien ${ }^{1}$, Paul Jacques Boncy ${ }^{2}$, Jean Frantz Lemoine ${ }^{3}$, Alexandre Existe ${ }^{2}$, Stanley Juin ${ }^{4}$, Sénou Amouzou ${ }^{1}$, Gabriel Thimoté ${ }^{5}$, Lesly Liverdieu Andrécy ${ }^{1}$, Samson Marseille ${ }^{3}$, Patrick Dély ${ }^{1}$, Wilnique Pierre ${ }^{1}$, Robert Barais ${ }^{1}$, Corvil Salomon ${ }^{1}$, Mentor Lucien ${ }^{2}$, Lottie Mondésir ${ }^{5}$, Khulood Rizvi', Dana M Parke ${ }^{6}$ and Marcus J Zervos ${ }^{6,7 *}$

${ }^{1}$ Direction d'Épidémiologie, de Laboratoire et de Recherches, Port-au-Prince, Haiti

${ }^{2}$ Laboratoire National de Santé Publique, Port-au-Prince, Haiti

${ }^{3}$ Programme National de Contrôle de la Malaria, Port-au-Prince, Haiti

${ }^{4}$ Haiti Center for Disease Control and Prevention, Port-au-Prince, Haiti

${ }^{5}$ Ministry of Health, Port-au-Prince, Haiti

${ }^{6}$ Henry Ford Health System, Detroit, MI, USA

'Wayne State University, Detroit, MI, USA

\begin{abstract}
Malaria continues to persist in Haiti, with 17,583 reported cases in 2015. The island of Hispaniola, the last locale of malaria in the Caribbean, recently adopted a bi-national agreement between the Dominican Republic and Haiti with the goal of eliminating malaria by 2020. In January 2015, the Laboratoire National de Santé Publique and Henry Ford Health System, in close collaboration with the Direction d'Epidemiologie, de Laboratoire et de Recherches, and the Programme National de Contrôle de la Malaria, hosted a Scientific Conference in Port-au-Prince, focusing on "Elimination Strategies for Malaria in Haiti." One year after this important conference, this article aims to evaluate the progress of malaria elimination in Haiti since new advanced strategies have been implemented, as well as to offer solutions to achieve this goal.
\end{abstract}

Abbreviations: RDT: Rapid Diagnostic Test; MSPP: Ministère de la Santé Publique et de la Population; PNCM: Programme National de Contrôle de la Malaria; LNSP: Laboratoire National de Santé Publique; HFHS: Henry Ford Health System; DELR: Direction d'Épidémiologie, de Laboratoire et de Recherches; RNSE: Réseau National de Surveillance Épidémiologique; SEBAC: Surveillance Epidémiologique à Base Communautaire

\section{Situational review}

Malaria, an important public health concern, continues to persist in Haiti $[1,2]$. The island of Hispaniola, the last locale of malaria in the Caribbean, recently adopted a bi-national agreement between the Dominican Republic and Haiti with the goal of eliminating malaria by 2020 [2].

Malaria infections in Haiti have been found to be predominantly caused by Plasmodium falciparum [1], with sporadic appearances of Plasmodium malariae [3]. The major malaria vector in Haiti is Anopheles albimanus [4]. Microscopy serves as the test of reference for confirming diagnosis of malaria in Haiti. Three brands of rapid diagnostic tests (RDT) are also authorized in Haiti to confirm malaria diagnosis. Additionally, the National Laboratory utilizes polymerase chain reaction-based assays (PCR) for research and evaluation purposes. National policy forbids presumptive treatment of malaria, requiring a biological diagnostic before any treatment [5]. The Ministère de la Santé Publique et de la Population (MSPP - Haitian Ministry of Health) considers chloroquine as the first-line drug for treating uncomplicated malaria in Haiti, with incorporation of primaquine [5].
The most recent national initiative to counter malaria in Haiti, the Programme National de Contrôle de la Malaria (PNCM), was created in 2005. PNCM's goals include: coordinating interventions, targeting coastal and low-altitude regions of Haiti, using microscopy or RDTs for all suspected malaria cases, ensuring that all diagnosed cases of malaria in Haiti be due only to imported cases, educating $80 \%$ of the population, and engaging in both passive and active surveillance [6].

In January 2015, the Laboratoire National de Santé Publique (LNSP) and Henry Ford Health System (HFHS), in close collaboration with the Direction d'Épidémiologie, de Laboratoire et de Recherches (DELR), and the Programme National de Contrôle de la Malaria, hosted a Scientific Conference in Port-au-Prince, focusing on "Elimination Strategies for Malaria in Haiti" [6]. The conference brought together laboratory personnel, researchers, clinicians, academics, and other stakeholders to discuss malaria elimination in Haiti. Main highlights of the conference included: the need for more information and research on malaria transmission and drug susceptibility of strains in Haiti; the need for additional training and resources to properly identify malaria cases; the need for elimination strategies to incorporate continued use of primaquine in addition to chloroquine, as well as active surveillance;

Correspondence to: Marcus J Zervos, Henry Ford Health System, 2799 W. Grand Blvd., Detroit, MI 48202, USA and Wayne State University, Detroit, MI 48201, USA; Tel: +1-313-916-2573; Fax: +1-313-916-2993; E-mail: mzervos1@hfhs.org

Key words: malaria, elimination, Haiti

Received: August 10, 2016; Accepted: August 28, 2016; Published: August 31, 2016 
and finally, the need for collaborative interdisciplinary approaches, sound strategic planning, funding, and strong ownership by the Ministère de la Santé Publique et de la Population [6].

The remainder of this article aims to evaluate the progress of malaria elimination in Haiti, since new advanced strategies have been implemented over the past year, as well as to offer solutions to achieve this important goal.

\section{Malaria in Haiti: 2015 Data}

In 2015, there were 17,583 reported cases of malaria in Haiti, compared to 17,094 reported cases in 2014. However, research estimates that up to 220,000 cases of malaria may be present in Haiti, with an estimated $80 \%$ of the Haitian population at risk for acquiring an infection [2,7-12].

Table 1 displays the number of malaria tests conducted and the distribution of positive cases of malaria in Haiti in 2015 by geographic department. Of these, the villages with the highest number of cases include: Jeremie [Grande-Anse-1,801], Delmas [Ouest-1,628], DameMarie [Grande-Anse-1,332], Roseaux [Grand'Anse-1,183], Croix des Bouquets [Ouest-1,077], Anse d'Hainault [Grand'Anse-777], and Port-au-Prince [Ouest-659]. These statistics represent the hospitals or clinics where cases of malaria are confirmed and reported to the MSPP, as coordinated by the DELR's surveillance on communicable and non-communicable diseases at sentinel sites (Réseau National de Surveillance Épidémiologique [RNSE] [5]).

These malaria data have limitations since there is variability in the use of microscopy and RDT, attributed to the fact that many health facilities in Haiti lack access to the tests, microscopes, or trained technologists. It is also suspected that there is a percentage of false positives reported via microscopy, since uninfected red blood cells may appear to contain a parasite where staining is poor or the observer is less experienced.

Another limitation of current reporting methods is that data is reported based on the location of the facility where the diagnosis occurred - not based on the location the patient resides, and thus, where the malaria transmission occurred. Often, patients travel long distances to receive quality care at larger health facilities; the data is thus misleading. For example, the city of Kenscoff in the Ouest Department reported 89 cases in 2015. However, the climate at this elevation is too cold to support parasite development and transmission by the Anopheles mosquito (the malaria vector); thus, the malaria transmission for these patients is likely occurring at a lower altitude.

\section{Public health challenges and perspectives}

Table 1. Number of Malaria Tests Conducted \& Number of Positive Malaria Tests inHaiti in 2015, by Geographic Department.

\begin{tabular}{|l|c|c|}
\hline Department & Number of Tests Conducted & Number of Positive Tests \\
\hline Artibonite & 37,334 & 1,132 \\
\hline Centre & 26,639 & 416 \\
\hline Grand'Anse & 28,397 & 6,974 \\
\hline Nippes & 12,844 & 825 \\
\hline Nord & 28,557 & 416 \\
\hline Nord-Est & 44,032 & 220 \\
\hline Nord-Ouest & 16,051 & 253 \\
\hline Ouest & 76,605 & 5,663 \\
\hline Sud & 21,665 & 1,187 \\
\hline Sud-Est & 10,616 & 497 \\
\hline TOTALS & $\mathbf{3 0 2 , 7 4 0}$ & $\mathbf{1 7 , 5 8 3}$ \\
\hline
\end{tabular}

Haiti faces many public health challenges. The country of Haiti has the lowest GDP in the Western hemisphere, and a health expenditure of $\$ 61$ USD per capita as of 2014, compared to a world average of $\$ 1,042$ USD [13]. The country's weak health system and infrastructure were further impacted by a magnitude 7.0 earthquake in January 2010, which devastated many healthcare and laboratory facilities in densely populated areas. Today, approximately 40 percent of the population lack access to essential health and nutrition services; coupled with the struggle of low human resources for health [14]. Many other health challenges exist, including 34,000 cases of cholera per year and probable lack of reporting on Zika virus outbreak in Haiti [15].

To compound these challenges, since March 2016, Haitian resident physicians have been on strike, closing almost all public hospitals in Haiti. This is the longest physician strike in Haiti in recent history. The physicians are striking for an increase in salary, which has remained stagnant over the last 20 years at approximately $\$ 120$ USD per month [16]; in addition to asking the government to provide them health insurance and security, and improve sanitation and infrastructure within Haiti's public hospitals [17]. Negotiations with the interim government have been ineffective, leading to a strike that is presently over three months in duration. Private hospitals and NGOs are overwhelmed with the influx of patients [18]; and the situation is dire for the poorest of the poor.In terms of malaria elimination, this strike is not only causing large public health challenges and limiting access to healthcare to seek prevention and treatment of malaria, it also is preventing these public hospital sites from reporting data on malaria which will cause a gap in malaria data for 2016 .

Globally, a variety of sociobehavioral barriers to prevention and treatment of malaria exist at individual, household, sociocultural, health infrastructure and policy and programmatic levels. For example, barriers include limited knowledge of prevention measures, negative perceptions of drug safety, logistical challenges relating to seeking treatment, poor delivery of supplies, insufficient funding, and slow scale-up of programs, among others [6].

One can expect similar barriers to exist in Haiti. A recent study examined knowledge of malaria and acute febrile illness in Port-auPrince and the Artibonite Département, finding that over $72 \%$ of respondents used traditional medication in addition to healthcare facilities for treatment of febrile illness [19]. Additionally, the study found that while respondents reported high knowledge on malaria, the number and types of sources of information they accessed for knowledge on malaria varied significantly by demographic characteristics [19]. These results have implications on how Haitians view malaria; however, more research needs to be conducted to fully understand the specific factors impacting prevention and treatment of malaria in Haiti.

\section{Recent malaria advancements: Globally and in Haiti}

There have been a variety of global advancements in the fight against malaria in recent years. Importantly, there is strong political commitment to eliminating malaria globally, from national and international organizations and governments [20]. This includes funding commitment; for example, Bill and Melinda Gates recently announced their aim to eradicate malaria globally by year 2040 supported with increasing funding [20]; however, additional financial resources will be required to achieve this goal.

Globally, many innovations are being developed in hopes to 
eliminate malaria, including, for example: new insecticides, a singledose cure, insecticide-treated wall liners, insecticide-embedded clothing, and genetically modified mosquitos, among others [21]. Additionally, the malaria vaccine candidate RTS,S/AS01 has shown efficacy in preventing a substantial number of cases of clinical malaria[22,23]; this vaccine could be an important tool in moving towards global elimination, and may have a potential role in Haiti's initiative for malaria elimination, particularly during the early period of vaccine administration.

In Haiti, a variety of important advancements have been made recently to eliminate malaria. Current interventions in Haiti include: vector control, distributing insecticide-treated nets, adoption of rapid diagnostic tests, utilizing the treatment combination of chloroquine plus primaquine, among other activities. In February 2015, Malaria Zero: The Alliance for a Malaria-Free Haiti, which includes the Ministries of Health of Haiti and of the Dominican Republic, was created aiming to eliminate indigenous cases of malaria on the island of Hispaniola by year 2020 [24,25].

The MSPP and the DELR have increased surveillance activities for malaria in 2016, including recruiting and deploying 100 new epidemiological surveillance officers in order to effectively monitor all municipalities of the country. Additionally, the DELR has operationalized community-based epidemiological surveillance (surveillance épidémiologique à base communautaire [SEBAC]) through several pilot projects, as well as revitalized and intensified active surveillance of cases (Adrien P, personal communication).

However, literature on malaria in Haiti generally suggests the need for more research to understand the complexities relating to elimination. A national cross-sectional survey of health facilities conducted in December 2012 demonstrates that the national prevalence of malaria among febrile outpatients is estimated to be $0.5 \%$; however, the limited availability of diagnostic tests contributes to over diagnosis and treatment [26]. A recent systematic review examined malaria vector research and control in Haiti; the limited and dated literature suggests that heavy investment in any single vector control approach should be avoided [27]. Other factors specific to Haiti need to be further studied: one study suggests after the 2010 earthquake, the rapid urbanization increased the amount of area with suitable habitats for mosquitoes, likely influencing mosquito ecology and posing challenges for introduction of vector-borne diseases [28]. There also have been recent studies on the genetic diversity of Plasmodium falciparum in Haiti [29], as well as on treatment of malaria including drug resistance [30,31]. However, continued research is needed to understand these factors in more detail in order to inform malaria elimination strategies.

\section{Moving forward: Community-based reduction of ma- laria transmission}

To move towards malaria elimination, there is a need for large scale, innovative interventions at all levels that will reach all populations at risk and with the goal to dramatically reduce malaria transmission. A community-based approach has many advantages and will enable Haiti to match resources to local burden, and allow affected communities to take a more aggressive approach to lowering and ultimately eliminating transmission in these high malaria infection areas [32].

Investment in health delivery at the community level has been shown to be successful in countries in Africa, the Americas and Asia. Investing in helping the communities and increasing demand for malaria control in affected communities improves the sustainability of the required high coverage with key interventions. In addition, the creation of coordinated community-based control in the foci of continued malaria transmission improves chances of eventual elimination. A communitybased approach has been shown to be cost effective and helps match resources to the local burden and to actual needs for control. Further, a community-based approach for reducing transmission of malaria makes it possible to reach the population at highest risk and to take advantage of existing systems that reach a large number of people. The critical additional components in the community-based approach for reducing transmission of malaria are: population-wide or focused screening and treatment of all infected individuals, active detection of malaria cases (symptomatic) or of infections (asymptomatic) in households, re-screening of the neighboring population, treatment of all infected persons and targeted focal vector control activities. These combined interventions are expected to further substantially reduce the transmission of malaria at the community level [32].

Certainly, data from field interventions and active household surveillance-in line with the DELR's community-based epidemiological surveillance (SEBAC) approach - are needed to determine where the vector resides and to target community-based elimination strategies for malaria in Haiti.

\section{Conclusions}

Over the past year since the 2015 Scientific Conference on Malaria Elimination, Haiti has made progress towards achieving this goal. Rates of malaria in Haiti have been decreasing over the past years, and the goal of elimination is quite possible. Moving forward, many factors will continue to play into the role of eliminating malaria in Haiti. Certainly, more information and research on malaria prevalence and transmission in Haiti are needed. Community-based initiatives will be crucial in reducing transmission of malaria. The PNCM and DELR's 2016 Operational Manual for Epidemiological Surveillance for the Elimination of Malaria in Haiti lays out a strong plan and guidelines for moving towards malaria elimination in Haiti [5]; continued support and funding will be needed to accomplish these activities. All activities will require collaborative, interdisciplinary approaches and strong ownership by the Ministère de la Santé Publique et de la Population in order to achieve zero transmission of malaria in Haiti.

\section{Competing interests}

The authors declare that they have no competing interests.

\section{References}

1. Raccurt C (2004) Malaria in Haiti today. Sante 14: 201-204. [Crossref]

2. Clinton Health Access Initiative Haiti MSPP/Programme National de Lutte Contre la Malaria and UCSF Global Health Group: The feasibility of malaria elimination on the island of Hispaniola, with a focus on Haiti: an assessment conducted January-June 2013. Port-au-Prince, Haiti. 2013.

3. Lindo JF, Bryce JH, Ducasse MB, Howitt C, Barrett DM, et al. (2007) Plasmodium malariae in Haitian refugees, Jamaica. Emerg Infect Dis 13: 931-933. [Crossref]

4. Desenfant P, Molez J-F, Richard A, Jacques J-R, Magloire R, Duverseau YT: Le paludisme en Haïti. 1. Sites d'étude et mise en évidence de sporozoïtes chez Anopheles albimanus Wiedmann, 1820. Cah Orstom Sér Ent Méd Parasitol 1987, 25:69-73.

5. Manuel Operationnel de Surveillance Epidemiologique pour l'Elimination de la Malaria. Programme National de Contrôle de la Malaria; Direction d'Epidémiologie de Laboratoire et de Recherches; 2016.

6. Boncy PJ, Adrien P, Lemoine JF, Existe A, Henry PJ, et al. (2015) Malaria elimination in Haiti by the year 2020: an achievable goal? Malar J 14: 237. [Crossref]

7. WHO: Informal consultation on fever management in peripheral health care settings: a global review of evidence and practice. Geneva, Switzerland: World Health Organization; 2013. 
8. Raccurt CP, Cicéron M, Dossil R, Boncy J (2012) [Prevalence of Plasmodium falciparum during the rainy season (June-December) in the southeast district of Haiti]. Med Sante Trop 22: 435-439. [Crossref]

9. Neuberger A, Zaulan O, Tenenboim S, Vernet S, Pex R, et al. (2011) Malaria among patients and aid workers consulting a primary healthcare centre in Leogane, Haiti, November 2010 to February 2011 - a prospective observational study. Euro Surveill 16. [Crossref]

10. Londono BL, Eisele TP, Keating J, Bennett A, Chattopadhyay C, et al. (2009) Chloroquine-resistant haplotype Plasmodium falciparum parasites, Haiti. Emerg Infect Dis 15: 735-740. [Crossref]

11. World Health Organization: Malaria country report 2011 - Haiti. 2011.

12. Roberts L (2010) Elimination meets reality in Hispaniola. Science 328: 850-851. [Crossref]

13. Pettigrew LM, Mathauer I (2016) Voluntary Health Insurance expenditure in low- and middle-income countries: Exploring trends during 1995-2012 and policy implications for progress towards universal health coverage. Int J Equity Health 15: 67. [Crossref]

14. USAID: Haiti Health Fact Sheet. USAID; 2016.

15. Miroff Nick (2016) While Latin American struggles over Zika, Haiti faces epidemic with a shrug. The Washington Post.

16. Carroll John (2016) Haiti’s Public Hospitals on Strike. Journal Star.

17. Carroll John (2016) Interview with Haitian Doctor On Strike. Journal Star.

18. Charles Jacqueline (2016) Forget Zika, Haiti has bigger problems - a doctors' strike Miami Herald.

19. Kaljee LM, Kilgore PE, Zervos MJ, Zervos JM, Parke DM, Arshad S, Chan C, Prentiss T, Prentiss K, Sime J: Healthcare Utilization for Acute Febrile Illness, Knowledge of Malaria and Trust in Informational Resources among Clinic Attendees in Port-auPrince and Artibonite Département: A Cross-sectional Survey. West Indian Medical Journal 2015.

20. Newby G, Bennett A, Larson E, Cotter C, Shretta R, et al. (2016) The path to eradication: a progress report on the malaria-eliminating countries. Lancet 387: 17751784. [Crossref]
21. Migiro Katy (2016) In the lab: six innovations scientists hope will end malaria. Thomson Reuters Foundation.

22. RTS,S Clinical Trials Partnership (2015) Efficacy and safety of RTS,S/AS01 malaria vaccine with or without a booster dose in infants and children in Africa: final results of a phase 3, individually randomised, controlled trial.Lancet 386: 31-45. [Crossref]

23. Olotu A, Fegan G, Wambua J, Nyangweso G, Leach A, et al. (2016) Seven-Year Efficacy of RTS,S/AS01 Malaria Vaccine among Young African Children. $N$ Engl $J$ Med 374: 2519-2529. [Crossref]

24. Tolchinsky Amy (2015) Consortium Aims to Eliminate Malaria on Hispaniola by 2020 Starting With \$29.9 Million Grant to CDC Foundation. CDC Foundation.

25. Rohner F, Tschannen AB, Northrop-Clewes C, Kouassi-Gohou V, Bosso PE, et al (2012) Comparison of a possession score and a poverty index in predicting anaemia and undernutrition in pre-school children and women of reproductive age in rural and urban Côte d'Ivoire. Public Health Nutr 15: 1620-1629. [Crossref]

26. Landman KZ, Jean SE, Existe A, Akom EE, Chang MA, et al. (2015) Evaluation of case management of uncomplicated malaria in Haiti: a national health facility survey, 2012. Malar J 14: 394. [Crossref]

27. Frederick J, Saint Jean Y, Lemoine JF, Dotson EM, Mace KE, et al. (2016) Malaria vector research and control in Haiti: a systematic review. Malar J 15: 376. [Crossref]

28. Samson DM, Archer RS, Alimi TO, Arheart KL, Impoinvil DE, et al. (2015) New baseline environmental assessment of mosquito ecology in northern Haiti during increased urbanization. J Vector Ecol 40: 46-58. [Crossref]

29. Carter TE, Malloy H, Existe A, Memnon G, St Victor Y, et al. (2015) Genetic Diversity of Plasmodium falciparum in Haiti: Insights from Microsatellite Markers. PLoS One 10: e0140416. [Crossref]

30. Carter TE, Boulter A, Existe A, Romain JR, St Victor JY, et al. (2015) Artemisinin resistance-associated polymorphisms at the K13-propeller locus are absent in Plasmodium falciparum isolates from Haiti. Am J Trop Med Hyg 92: 552-554. [Crossref]

31. Okech BA, Existe A, Romain JR, Memnon G, Victor YS, et al. (2015) Therapeutic efficacy of chloroquine for the treatment of uncomplicated Plasmodium falciparum in Haiti after many decades of its use. Am J Trop Med Hyg 92: 541-545. [Crossref]

32. WHO: Community-based Reduction of Malaria Transmission. 2012.

Copyright: @2016 Adrien P. This is an open-access article distributed under the terms of the Creative Commons Attribution License, which permits unrestricted use, distribution, and reproduction in any medium, provided the original author and source are credited. 